\title{
Evaluating the Conspectus Approach for Smaller Library Collections
}

\section{Larry R. Oberg}

The conspectus method of collection evaluation has been successfully used since the late 1970s by the large member libraries of the Research Libraries Group and the Association of Research Libraries. Today, the Library and Information Resources for the Northwest (LIRN) and other conspectus-based collection assessment projects are demonstrating the value of this approach to smaller university, college, and public libraries as well. This article reviews the LIRN project, the LIRN modifications to the original RLG instrument, and the conspectus process. It also discusses conspectus methodology problems, staff time costs, and the value of the completed conspectus to an individual library or group of libraries.

ne of the most vexing problems facing academic librarians, indeed all librarians, is the lack of adequate, reliable tools for evaluating our collections and services. We measure what is easiest to measure, Goldhor notes, most often process or input, not output variables. ${ }^{1}$

Many of our traditional measures have been subjective and impressionistic and remain so today. For example, we determine the quality of our reference services by measuring patron satisfaction, the number of scheduled desk hours, and staff educational level and years of experience. Yet these determinants are ancillary to what we really want to know, which is, How accurate are our responses to patron questions?

We have not done much better evaluating our collections. We seem unable to compare them to the total universe of information or with collections in similarly sized institutions. Often, we do not know how well they match the curriculum and meet the needs of students and faculty.

In the face of proliferating new publications, severe inflationary pressures, and increasingly sophisticated competition at budget time, we cannot effectively compete for static or dwindling funds by arguing that we need more money because we have too few books or by reminding our provosts that the library is the heart of the institution. Instead, we must seek out, develop, and utilize measures that demonstrate objectively, both to administrators and to ourselves, how well we are fulfilling our role and mission.

Faculty and administrators, if they are to support our programs, must be reassured that requests for increased funding derive from a systematic, sustained planning and evaluation process. We must convince them that we are spending their money wisely by measuring, in other than subjective terms, the collection and service improvements resulting from higher-level funding.

One method of collection evaluation,

Larry R. Oberg is Director of Libraries at Albion College, Albion, Michigan 49224. This article expands upon a paper read at the Liberal Arts College Library Directors' Meeting, Grinnell College, Grinnell, Iowa, October 19, 1987. 
the conspectus, fulfills at least some of our needs. This paper describes the conspectus collection evaluation process, discusses its problems and cost in staff time, and demonstrates its usefulness to smaller college, university, and public libraries.

\section{THE CONSPECTUS}

The conspectus is a collection assessment method that maps subject strengths and weaknesses within an individual library, a consortium of libraries, or a geographical region using standardized criteria and descriptions. The dictionary definition of conspectus is a survey or synopsis of a subject, but in library parlance it refers to an assessment methodology developed in the late 1970 s by Paul Mosher of Stanford University and other Research Libraries Group (RLG) collection development officers for use by RLG librarians. ${ }^{2}$

\section{"The conspectus was designed to produce comparable data to facilitate collection coordination among the large RLG libraries."'}

The conspectus was designed to produce comparable data to facilitate collection coordination among the large RLG libraries. Mosher recalls that the goal of the original development group was to describe "all major U.S. research libraries as part of the largest scholarly research resource collection the world has ever known. ${ }^{\prime 3}$

Since its introduction by RLG, the conspectus has been adopted by the North American Collections Inventory Project (NCIP). Developed in 1983 by the Association of Research Libraries' Office of Management Studies, NCIP is using the conspectus to generate data for an online inventory of North American research collections to assist scholars in finding the research materials they need. ${ }^{4}$

Conspectus methodology is used by North American academic and public libraries of all sizes and, increasingly, by foreign libraries as well. In addition to individual institutions such as Albion College Library, groups using the conspectus in the United States include the Alaska Statewide Inventory Project, the Illinois Statewide Collection Development Project, New York's METRO (Metropolitan Reference and Research Library Agency), Idaho's VALNet (Valley Library Network), ${ }^{5}$ the Boston Library Consortium's Collection Analysis Project, and the Library and Information Resources for the Northwest (LIRN), a regional project established in 1984 and underwritten by the Fred Meyer Charitable Trust, a private foundation located in Portland, Oregon. ${ }^{6}$

\section{LIRN}

LIRN's thrust was fourfold. It sought to assess the depth and quality of the information resources available in the region; establish a shared database for manipulating, analyzing, and displaying the information generated by the assessment; foster and encourage cooperation and resource sharing among all types and, importantly, all sizes of libraries; and finally, establish a technologically advanced regional document delivery system for costeffective information exchange.

The first charge to those of us who participated in the LIRN project was to locate or develop a methodology to assess the collections of large research institutions, small colleges, and special and public libraries of all sizes. The only instrument that held promise of fulfilling our needs was the RLG conspectus. It was modified to more precisely describe the collections of the many small libraries of the region that were expected to participate. The LIRN version is called the Pacific Northwest Conspectus.

Today, the LIRN assessment program is moving toward completion. More than 210 Pacific Northwest libraries, both large and small, academic, special, and public, are finishing or have finished at least some of the twenty-four basic subject divisions of the conspectus. ${ }^{7}$ The data collected are reported to the Pacific Northwest Conspectus Database operated by the Oregon State Library Foundation in Salem. Textual and graphic reports comparing collec- 
tions at varying levels of specificity by library location, type, budget, funding source, school enrollment, etc. are produced in batch mode. ${ }^{8}$

\section{THE ASSESSMENT PROCESS}

The Library of Congress classification system (LC) forms the general framework of the original conspectus, although LIRN has developed a Dewey-based version as well. Subsets of the collection-subjectsare evaluated and ranked on a scale of 0 to 5.

The Pacific Northwest Conspectus begins with a subject-by-subject examination of a library's collection. Each subject or subset of a subject is given three separate numerical ratings that rank the existing collection level (CL); the acquisitions, or monetary, commitment (AC); and the target level or collection goal (GL). The acquisitions commitment and the collection goal may be higher or lower than the current collection level.

The subject rankings are amplified by language codes: E, predominately English; F, selected foreign-language titles; $\mathrm{W}$, wide selection of foreign-language titles and; $\mathrm{Y}$, primarily foreign-language titles. Detailing language coverage adds a significant dimension to the description of a collection. The alphanumeric values assigned to each subject, for example, 3AF, are then recorded on the conspectus work sheets.

Completion of the work sheets requires concise comments to describe strengths, weaknesses, and other characteristics of the cataloged collection that are not brought out by the LC or Dewey classification systems. Examples of these comments are "strong in pre-1960s materials," "good representation of 19thcentury authors," and "have all editions of the International Encyclopedia of the Social Sciences." The comments are included in the note section of the work sheets.

Materials not classified in the LC or Dewey systems, for example, theses, government documents, journals, newspapers, special collections, microforms, films, electronic databases, etc., are also described. Examples of these notations are "strong in U.S. government documents," "weak journal collection," and "have excellent uncataloged radical culture collection from the 1960s." In the Pacific Northwest Database, the comments, which may be up to ninety characters in length, are retrieved in textual reports (see figures 1-3).

\section{EXAMINING THE COLLECTION}

For the most part, the methods used to examine collections are traditional. They include shelf scanning, list checking, the compilation of statistics, and citationreference studies. But any method that sheds light on the depth of a collection may be employed. ${ }^{9}$

Shelf scanning, a lost art for many librarians, produces immediate and tangible results by revealing broken runs of serials, little or heavily used materials, a lack of up-to-date materials, and other lacunae or strengths. It is accomplished quickly and easily and builds upon the subject expertise of teaching faculty and librarians.

List checking is the most time-honored method of collection evaluation. Specialized and selective lists are published in most subject areas by accrediting bodies, professional associations, researchers, bibliographers of all stripes, librarians, and, of course, the American Library Association. A major tool for this type of assessment becomes available in 1988 when ALA publishes the third edition of Books for College Libraries.

The subject experts most likely to be pressed into service by academic librarians are the teaching faculty. On most college campuses, teaching faculty share selection responsibilities with librarians and, in any event, are familiar with the bibliographical resources of their subject specialties.

The compilation of statistics and various numerical counts provides useful information on the quality of a collection. Expenditures, the number of volumes added per year, shelflist counts, the relative strength and use of the book and the periodicals collections, and an analysis of interlibrary loan and circulation patterns are examples of statistics usefully gathered for conspectus-based collection assessments. 
Division: CHEMISTRY

Library: Date:

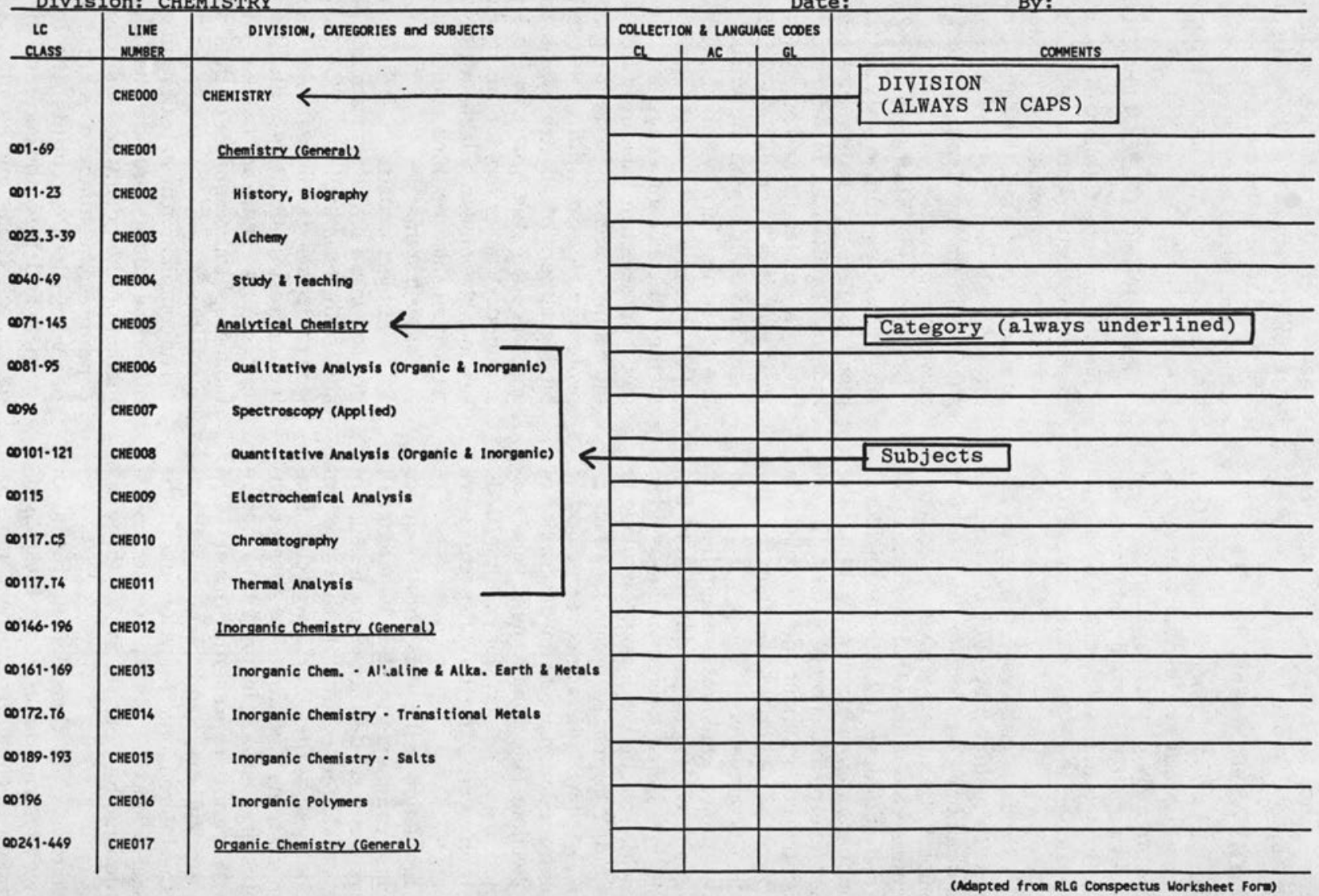

FIGURE 1

Pacific Northwest Conspectus Work Sheet-LC-Version 11/87, page 1 


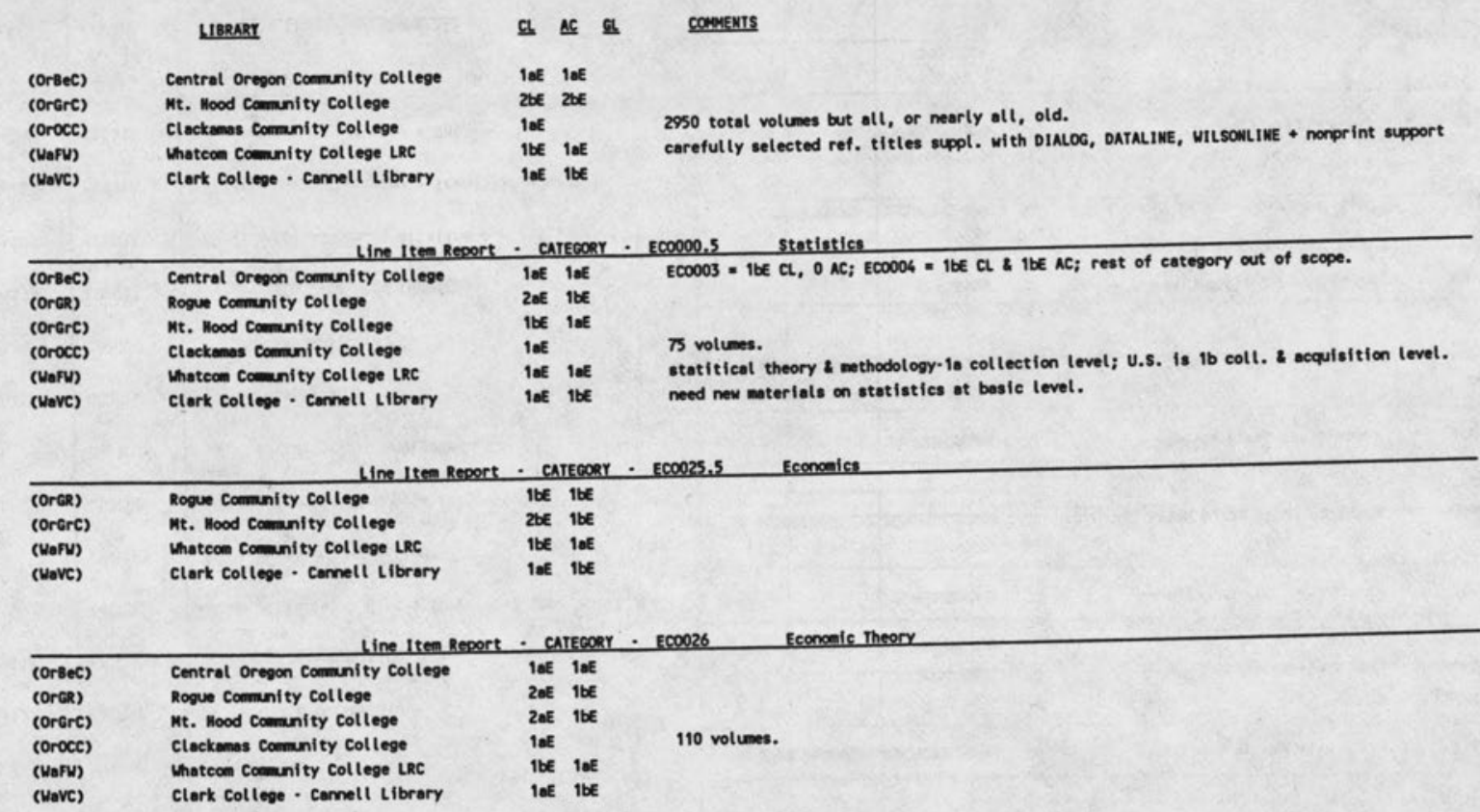

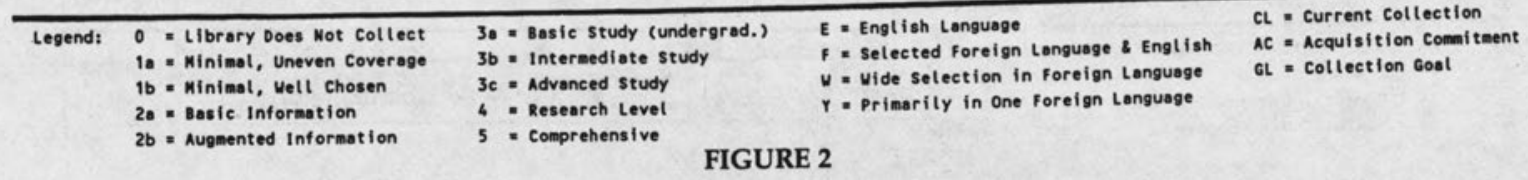

Oregon and Washington Community Colleges-All LC Categories in the Business and Economics Division 
AGRICULTURE

Id

Idaho state Library

10

Boise Public Library

$1 \mathrm{dBe}$

Boise State University Library

IdCN

Worth Idaho college Library

Idco

Calduell public Library

Id W

IorR

Idsp

Idss

Idif

IdU-L

Ricks College, David Mckay LRC

East Bomer county Library

Soda Springs Public Library

Twin Falls Public Library

University of Idaho - Law Library

d.

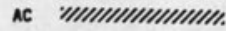

ac "IIIIIIIIIIIIIIIIIIIIIIIII,

ac "rrmIrIIn.

\begin{tabular}{|c|c|c|c|c|}
\hline Legend: & $\begin{array}{l}\text { MA }=\text { Mot Assessed } \\
0=\text { Library Does Not Collect } \\
1 \mathrm{a}=\text { Minimal, Uneven Coverage } \\
1 \mathrm{~b}=\text { Minimal, Well Chosen }\end{array}$ & $\begin{array}{l}2 a=\text { Basic Information } \\
2 b=\text { Augmented Information } \\
3 a=\text { Basic Study (undergrad.) } \\
3 b=\text { Intermediate Study }\end{array}$ & $\begin{array}{l}3 c=\text { Advanced Study } \\
6=\text { Research Level } \\
5 \text { = Comprehensive }\end{array}$ & $\begin{array}{l}C L=\text { Current collection } \\
A C=\text { Acquisition Commitment } \\
G L=\text { Collection Gost }\end{array}$ \\
\hline
\end{tabular}

$1 \mathrm{a}=$ Minimal, Uneven Coverage
$1 \mathrm{~b}$. Minimal, Well Chosen

$3 b=$ Intermediate study

\section{FIGURE 3}

Division Comparative Report-Idaho Libraries-Agriculture Division 
Citation-reference studies, essentially locally developed critical bibliographies, are constructed when reliable published lists are not available. These studies are useful for assessing emerging and interdisciplinary fields.

All or a combination of these and other methods of collection evaluation may be used in the conspectus collection evaluation process, the configuration chosen varying from subject to subject. For example, measuring the shelflist is not a particularly productive technique in a field such as chemistry where scholarly communication is carried on almost exclusively through the journal literature.

In sum, librarians rely upon their professional judgment to choose the appropriate combination of assessment methods, to recognize when a subject has been adequately analyzed, and to assign the numerical values.

\section{ASSIGNING COLLECTION LEVEL CODES}

When the evaluation of a subject is completed, the numerical values to be assigned are entered on the conspectus work sheets. These values range from 0 , or out-of-scope, through 5 , or comprehensive. Levels 1 through 3 are subdivided by the letters $A$ and $B$. The finer distinctions made possible by the subdivision of the three lower levels, unnecessary for the very large libraries using the original conspectus, were adopted by LIRN from Alaska Statewide Inventory Project practice. These subdivisions make possible more accurate description of smaller collections.

These numeric values are preferably referred to as collection level codes, but sometimes as collection intensity level indicators. ${ }^{10}$ Each collection level code has a standard definition that describes the types of client activities supported by collections developed to that depth. These descriptions serve as the authority for assigning the codes. For example, a 2B-level collection supports instruction through the lower division or the basic information needs of public and special library patrons; a 3B-level collection supports in-

\section{"The conspectus is collection, not cli- ent, based."}

struction through the master's level or the advanced independent study needs of public and special library clientele.

The conspectus is collection, not client, based. The collection level codes refer to the quantity and types of materials that are included and do not rate the collection as good or bad. Thus, a collection developed to a lower code level may quite adequately meet the information needs of a particular clientele.

In the past, groups adopting the conspectus, including RLG, NCIP, the Alaska Statewide Inventory Project, and LIRN, have developed their own descriptions of the client activities that each collection level code supports. A proposed uniform code structure for all libraries was recently developed by Marcia Pankake and Joseph J. Branin of the University of Minnesota. Prepared for inclusion in the new edition of the ALA Guidelines for Collection Development, the Pankake-Branin codes were approved in January 1988, at ALA's Midwinter Meeting.

At Albion College, librarians are using these codes in draft form to assess their collections and expect them to emerge as the national standard.

\section{LEVELS OF SPECIFICITY}

The Pacific Northwest Conspectus offers the possibility of evaluating subjects at three hierarchically ordered levels of specificity, division, category, and subject. At the division level, 24 subjects are ranked; at the category level, 500; and at the subject level, somewhat less than 4,000 .

The category, or 500 subject level, does not occur in the RLG conspectus and was developed by LIRN from National Shelflist Count subject ranges for the Pacific Northwest version. LIRN-developed Dewey and LC work sheets are available at the category and subject levels.

The subdivision of the three lower collection level codes, the development by 
LIRN of the Dewey work sheets, and the category level of assessment are contributions of great importance to the profession. LIRN's work sheets, training manual, and database software are available to librarians outside of the region. ${ }^{11}$

In assessing their collection of approximately 380,000 volumes, Albion College librarians found the subject level the most useful, although the conspectus approach allows free movement from one level to another. For example, librarians who collect little or nothing at all in agriculture may wish to rank that subject at the division level, indicating that their library has a $1 \mathrm{~A}$ or even a 0 -level collection.

On the other hand, with a particularly weak, strong, or uneven collection in biology, the librarian may choose to rank individually all twenty-five subdivisions of fungi at the detailed subject level to emphasize these characteristics. At the category level, fungi is not subdivided and requires a single ranking. It is appropriate to move freely between division, category, and subject levels to describe strengths and weaknesses.

\section{VALIDATION OF DATA}

Various techniques are employed to ensure accuracy and comparability between the collection level codes assigned by librarians at different institutions. Librarians using the conspectus in consortial arrangements organize group training programs, use or develop standard training materials and methods, and conduct validation studies. Inconsistencies in reporting data are also noted and corrected through continuing entry, use, and comparison of the data.

The Pacific Northwest Conspectus Database staff report that some discrepancies are occurring in the data reported to them, particularly at the two and three levels. Staff members are developing a method for validating data reported at the particularly troublesome 3-A level. ${ }^{12}$

At Albion College, responsibility for completing the different divisions of the conspectus is assigned to individual librarians. However, the completed work sheets are reviewed in detail by all librarians participating in the project.

\section{WHAT IT COSTS IN STAFF TIME}

Completing the conspectus may appear to be a daunting prospect. Indeed, anyone contemplating it should weigh the cost in staff time against the benefits. Further, the conspectus is a living document that requires continuous review and revision. Flexibility can be exercised in scheduling its completion, however, and librarians may choose to complete only some of its twenty-four primary divisions.

At Albion College, librarians plan to complete all divisions of the Pacific Northwest Conspectus within a two-year period. They estimate that an average of fifty-five hours is required to evaluate a division at the subject level and somewhat less at the category level. Of these hours, librarians use approximately twenty-five; paraprofessionals, twenty; and faculty, ten. The amount of time required to complete the conspectus will vary, of course, from institution to institution.

\section{THE VALUE OF A COMPLETED CONSPECTUS}

The completed conspectus constitutes a detailed overview or map of a collection that is different from and complementary to title-based inventories, for example, OCLC and RLIN. The work sheets serve as the core of any collection development or coordinated cooperative collection development policy statement and as important selection tools for faculty and librarians. The data contained on the work sheets permit detailed comparison of local collections with collections in other libraries where librarians have also completed the conspectus.

The conspectus work sheets are used manually for many functions, but statistical reports and comparative studies are generated more efficiently and effectively when the data are entered into a common database shared by a group of libraries. The detailed comparative reports that it is then possible to produce are essential to librarians who have or plan to have coordinated cooperative collection development arrangements with other libraries.

Whether or not an automated database 
is established, the completed conspectus provides librarians with the data necessary to respond systematically to budget reductions or increases and changes in institutional roles and missions, curriculum, and user patterns. In a word, it gives us a rational basis for initiating and reacting to change.

At the local level, perhaps the most important outcomes are measured in human terms. The skills of the librarians who participate in the conspectus process are upgraded. Mosher suggests that librarians "communicate more knowledgeably about their collections," are better prepared to make selection and management decisions, and "generally take better control of the collection under their stewardship." 13

Teaching faculty also improve their selecting skills and knowledge of the library through their participation. They come to understand that a good collection is more than the sum of the books they have requested for purchase and that the process of building excellent collections involves more than judicious selection.

The conspectus assessment process encourages bonding between teaching faculty and librarians and reassures teaching faculty that the collecting goals of librarians correspond to their needs and those of their students. At Albion College, completing the conspectus is generating a high level of interaction between teaching faculty and librarians. Through this collaborative process, which includes rational discussion and heated argument, a shared vision of our collecting goals is emerging.

Finally, the completed conspectus is an excellent tool for communicating with college administrators and funding agencies. It can generate powerful arguments for improved budgets and assures those to whom we report that we understand, control, and accurately predict our programs, in effect, that optimum use is being made of the funds they grant us.

Many of these benefits accrue through the process of completing the conspectus. If the assessment is hastily or inadequately prepared by librarians who rely too heavily upon their intuitive knowl- edge of their collections and fail, for example, to call upon the expertise of the teaching faculty, the accuracy of the final report is cast in doubt, and its value as a selection tool and guide to the collection diminished. The incremental process, not simply the product, generates value to the individual librarian, the library, the faculty, and the parent institution.

\section{PROBLEMS WITH THE CONSPECTUS}

The original RLG conspectus and the Pacific Northwest Conspectus are not without flaws. For example, unexplained gaps exist in the ranges of classification numbers included on the LC work sheets. Differences are found between the wording of the subjects in the LC classification schedules and the wording on the work sheets. The Dewey and LC work sheets, comparable at the division level, cannot be compared exactly at the category and subject levels. Further, participating in the assessment process brings teaching faculty uncomfortably close to LC subject organization incongruities, which they find difficult to accept. Nonetheless, these problems are insignificant when compared to the magnitude of the conspectus process.

\section{CONCLUSIONS}

We know that the conspectus well serves large research libraries linked together in cooperative arrangements. The LIRN program and others like it are demonstrating that, used either individually or collectively, the conspectus can be a valuable tool for the smaller academic and public libraries as well.

Albion College librarians are completing the conspectus outside a consortium of like-minded colleagues. They believe that the results justify the investment of time

\footnotetext{
"By completing the conspectus, we contribute directly to the embryonic effort to inventory and describe the information resources that support our cultural and economic development as a nation."
} 
and effort even though completion does not promise the immediate benefits of interinstitutional comparison. They do expect, however, that other libraries or groups of libraries with which they identify will come to join them in completing the conspectus. Then, intensified consortial, shared, and coordinated cooperative collection development arrangements will be possible, and the value of the local assessment enhanced.

Collection development is one of our most complex and intellectually challenging tasks. The conspectus is the best in- strument we have for analyzing, evaluating, maintaining, and coordinating what is our most fundamental charge as librarians, the collection. By completing the conspectus, we contribute directly to the embryonic effort to inventory and describe the information resources that support our cultural and economic development as a nation.

The conspectus is not a perfect tool. It will not solve all of our collection development problems, but it has begun to serve us well.

\section{REFERENCES AND NOTES}

1. Herbert Goldhor, "Preface," in F. W. Lancaster, The Measurement and Evaluation of Library Services (Arlington, Va.: Information Resources Pr., 1977), p.vii.

2. Nancy E. Gwinn and Paul H. Mosher, "Coordinating Collection Development: The RLG Conspectus," College \& Research Libraries 44:128-39 (Mar. 1984).

3. Paul H. Mosher, "A National Scheme for Collaboration in Collection Development: The RLGNCIP Effort," Resource Sharing and Information Networks, 2:31 (Spring/Summer 1985). Also published in Coordinating Cooperative Collection Development: A National Perspective; Proceedings of the Conference, ed. Wilson Luquire (New York: Haworth Pr., 1986), p.31.

4. Jutta Reed-Scott, Draft Manual for the National Inventory of Research Collections, Preliminary ed. (Washington, D.C.: Association of Research Libraries, Office of Management Studies, 1984), p.1.

5. Larry R. Oberg, "A Model of Cooperation: The VALNet Project," Library Journal 111:50-53 (Nov. 15, 1986).

6. Anne Haley and Douglas K. Ferguson, "The Pacific Northwest Collection Assessment Project," Resource Sharing and Information Networks 2:185-97 (Spring/Summer 1985). Also published in Coordinating Cooperative Collection Development: A National Perspective; Proceedings of the Conference, ed. Wilson Luquire (New York: Haworth Pr., 1986).

7. Peggy Forcier, Director, Pacific Northwest Conspectus Database, personal communication, 1987.

8. Peggy Forcier, "Building Collections Together: The Pacific Northwest Conspectus," Library Journal, 113:43-45 (Apr. 15, 1988).

9. Descriptions of most standard collection assessment methods are included in Blaine H. Hall, Collection Assessment Manual for College and University Libraries (Phoenix, Ariz.: Oryx, 1985).

10. For a discussion of collection level codes, their functions and problems, see Ross Atkinson, "The Language of the Levels: Reflections on the Communication of Collection Development Policy," College \& Research Libraries 47:140-49 (Mar. 1986).

11. Pacific Northwest Collection Assessment Manual (Portland, Ore.: Fred Meyer Charitable Trust; Library and Information Resources for the Northwest, 1986), 90p; information on these products may be obtained from Peggy Forcier, Director, Pacific Northwest Conspectus Database, State Library Building, Salem, OR 97310-0642.

12. Peggy Forcier, Pacific Northwest Conspectus Database, personal communication, 1987.

13. Paul Mosher, "A National Scheme," p.31. 